\title{
Association of toll-like receptor (TLR) 2, 7 and 9 gene polymorphism with hepatitis $A$ virus infection risk in population of Assam, India
}

\author{
Priyanka Kashyap*1, Manab Deka1, Sangit Dutta ${ }^{2}$ and Namrata Kumari ${ }^{1}$ \\ ${ }^{1}$ Department of Bioengineering and Technology, Laboratory of Molecular Virology \& Oncology, Gauhati \\ University, Guwahati, Assam, India \\ ${ }^{2}$ Department of Medicine, Gauhati Medical College, Guwahati, Assam, India \\ *Priyanka Kashyap, Department of Bioengineering and Technology, IST, Gauhati University, Guwahati, India
}

\begin{abstract}
Hepatitis A is one of the most common causes of acute viral hepatitis worldwide. Hepatitis A infection can also result in a cholestatic hepatitis or a relapsing course or fulminant liver failure. TLR polymorphisms have been implicated in susceptibility, pathogenesis and progression of viral hepatitis.The aim of the present study was to investigate the role of TLR 2 (rs5743708), TLR7 (rs179009) and TLR9 (rs5743836) polymorphism with association of HAV infection risk in population of Assam. The SNP study was performed by genomic DNA extraction followed by PCR-Restriction Fragment Length Polymorphism (RFLP) and the genotypic and allelic frequency distributions were analyzed.Statistical analysis was performed by SPSSv13.0 software. The presence of variant allele A of TLR2 rs5743708 significantly increased the risk of cholestasis compared to controls $(\mathrm{p}=0.004)$ [OR=2.5 (1.328- 4.808) at 95\%CI]. The TLR7 polymorphism rs 179009 was not found to be significantly associated with HAV infection and sisease severity. The presence of the mutant allele T significantly increased the risk of acute HAV $[\mathrm{p}<0.0001 ; \mathrm{OR}=10.07$ (5.242- 19.97) at 95\%CI] , HAV with cholestasis $[\mathrm{p}<0.0001 ; \mathrm{OR}=5.05$ (2.784- 9.324) at 95\% CI] and FHF $(\mathrm{P}<0.0001 ; \mathrm{OR}=8.5(4.542-16.64)$ at $95 \% \mathrm{CI})$. Our results provide first evidence for the TLR2 rs5743708 polymorphism as a host factor affecting HAV infection and thus the disease severity. TLR9 rs5743836 was found to be a significant risk factor for HAV disease severity.
\end{abstract}

KEY WORDS: CHOLESTASIS, FULMINANT, HEPATITITS A, POLYMORPHISM, TOLL LIKE RECEPTOR.

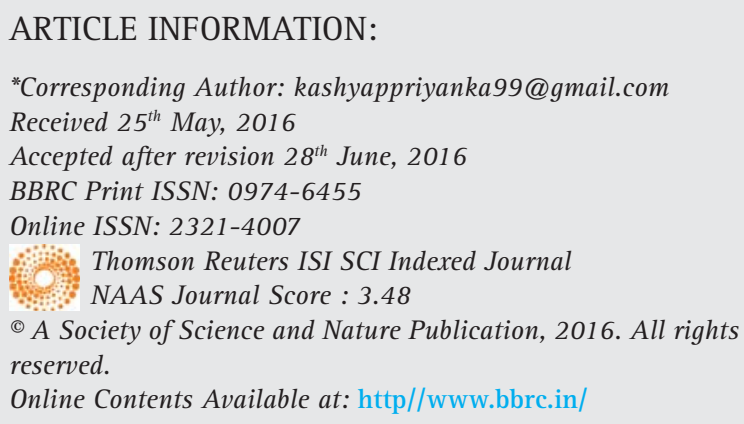




\section{INTRODUCTION}

Hepatitis A is one of the most common causes of acute viral hepatitis worldwide (MMWR.,1996). Globally, an estimated 1.4 million cases of hepatitis A virus (HAV) infection occur annually. The liver injury from hepatitis A infection is usually mild, mostly in children, where it is frequently subclinical. But in adults, infection with hepatitis A can result in acute or fulminant liver failure. Hepatitis A infection can also result in a cholestatic hepatitis or a relapsing course (Glikson et al.,1992). The reported overall case-fatality rate of hepatitis A is between $0.01 \%$ to $0.03 \%$; however, it is believed to be much higher in adults. Hepatitis A virus (HAV) belongs to the genus Hepatovirus within the family Picornaviridae and contains a positive-sense, single-stranded RNA genome of approximately $7.5 \mathrm{~kb}$ in length (Yokosuka., 2000 and Buggs 2016).

TLRs recognize a wide variety of pathogen associated molecular patterns (PAMPs) from a wide range of host like bacteria, viruses, and fungi, as well as some other host molecules (Aderem and Ulevitch.,2000). TLR's play a key role in the pathophysiology of a range of human diseases, including cancer. TLR2 gene is located on chromosome 4 and recognizes conserved molecular patterns (e.g. lipopolysaccharide (LPS) on bacteria which are major inducers of the inflammatory response. It is involved in the innate immune system (Medzhitov.,2001) and TLR2 is capable of detecting the widest repertoire of pathogen-associated molecular patterns from a large variety of pathogens, including gram-positive or gramnegative bacteria, myco bacteria, fungi, viruses, and parasites.

Genetic studies on the TLR2 gene have identified a number of polymorphisms which have been shown to affect host defense and disease progression (Chen et al.,2010; Takeda et al., 2003). TLR 2 SNP rs5743708 is associated with tuberculosis, staphylococcal septic shock, heart restenosis, Lyme disease and cytomegalovirus (CMV) disease after liver transplantation (Ogus et al., 2004;Lorenz et al., 2000; Schro"der et al., 2005; Kijpittayarit et al., 2007). Also it correlates with transplant rejection and higher mortality of chronic hepatitis C patients (Eid et al., 2007).

TLR7 is mainly expressed in the endosome-lysosome membrane of plasmacytoid dendritic cells (pDCs), hepatic natural killer cells, and B lymphocytes. TLR7 recognises ss viral RNA which are released upon phagocytosis when phagocytes take up a virus or virus-infected apoptotic cell.

TLR9 is localized intracellularly mostly in the endocytic compartments and TLR9 recognizes unmethylated $\mathrm{CpG}$ motifs present in bacteria and viruses (Pandey et al., 2006). TLR9 functions through the MyD88 dependent pathway leading to NF-kappa-B activation, cytokine secretion and the inflammatory response. TLR9 rs5743836 polymorphism has been demonstrated to predispose to Hodgkin lymphoma, as well as to several autoimmune and chronic inflammatory diseases like asthma and Crohn's disease (Hong et al.,2007; Lachheb et al., 2008; Lazarus et al., 2003; Mollaki et al., 2009; Torok et al., 2004).

The role of host genetic factors in determining susceptibility to infections has become more evident; some persons may be predisposed to certain infections, whereas others are protected (Hill, 2001). Evidence suggests that single nucleotide polymorphisms (SNPs) in the TLR genes impair the ability to respond to different type of infection (Weltzler., 2003). And so we hypothesise that a better understanding of the HAV disease infection may be achieved by studying the TLR2, TLR7 and TLR9 gene polymorphism of the susceptible and resistant persons may contribute to the HAV infection severity. The aim of the present study was to investigate the role of TLR 2 (rs5743708), TLR7 (rs179009) and TLR9 (rs5743836) polymorphism with association of HAV infection risk in population of Assam.

\section{MATERIAL AND METHODS}

Study subjects: A total of 179 patients with HAV infection were included in the study between 2012 and 2014 with prior written informed consent. An almost equal number of age- and sex- matched healthy controls (voluntary blood donors) who had no history of hepatitis, hepatobiliary diseases, negative for HAV IgM and autoimmune hepatitis, were also included in the study. Patients were enrolled from general OPD and Medicine Ward of Gauhati Medical College and Hospital (GMCH), Guwahati, Assam on the basis of clinical investigation, positive for HAV IgM using $3^{\text {rd }}$ generation ELISA kit and confirmed by HAV detection PCR spanning a region of 154 b.p. for VP1 region. Patients who were positive for other hepatotropic virus, HIV, autoimmune hepatitis, alcoholic and drug abuse were excluded. The study was approved by the institutional ethical committee of Gauhati University, Guwahati.

In this study, prolonged cholestasis was defined as that with total bilirubin level $\geq 5 \mathrm{mg} / \mathrm{dL}$ lasting for more than 4 weeks after admission (Jung et al., 2010) . Acute liver failure according to the widely accepted definition of acute liver failure that states there would be evidence of coagulation abnormality, usually a prolongation of PT by INR $\geq 1.5$ or prothrombin time $>15$ seconds, and any degree of mental alteration (encephalopathy) in a patient without pre-existing cirrhosis and with an illness with duration <26 weeks (Polso and Lee., 2005). 


\section{DNA EXTRACTION}

Blood samples $(5.0 \mathrm{ml})$ from HAV patients and control subjects were collected in EDTA vials and stored at $4{ }^{\circ} \mathrm{C}$ until required. Genomic DNA was extracted from whole blood by standard Proteinase-K digestion and phenol/ chloroform extraction procedure.

\section{GENOTYPING}

TLR2 (rs rs5743708), TLR7 (rs179009) and TLR9 (rs5743836) genotypes were determined by a polymerase chain reaction (PCR) method, and were genotyped by PCR-Restriction Fragment Length Polymorphism (RFLP). The PCR product of 152 b. p. of TLR2 rs5743708 was amplified using the set of primers 5'-GCTGCCATTCTCATTCTTCTG-3'and5'-CGCAGCTCTCAGATTTACCC-3' and digested with the restriction enzyme Pst1 (MBI Fermentas, USA) at $37^{\circ} \mathrm{C}$ overnight, and then analyzed on 2.5\% agarose gel electrophoresis. A single band of 152 b. p. characterised wild type $G$ allele, while the presence of three bands at 152, 85 and 67 b.p. or two bands at 85 and 67 b.p. only characterises heterozygous and homozygous variant respectively (A allele is the mutant allele).

The PCR product of 190 b. p. of TLR7 rs179009 was amplified using the set of primers 5'- ATTTGCTGCCTCTCTTTTGC-3' and 5'-GCTGCTTCTACCCTCTCGAA-3' and digested with the restriction enzyme Hin1 (MBI Fermentas, USA) at $37^{\circ} \mathrm{C}$ overnight, and then analyzed on 2.5\% agarose gel electrophoresis. A single band of $190 \mathrm{~b}$. p. characterised mutant type $\mathrm{C}$ allele, while the presence of three bands at 190, 104 and 86 b.p. or two bands at 104 and 86 b.p. only characterises heterozygous and homozygous variant respectively ( $\mathrm{T}$ allele is the wild allele).

The PCR product of 164 b. p. of TLR9 rs5743836 was amplified using the set of primers 5'-GCAAAGGAGCTCAGGAGTG-3' and 5'-GCCTTGGGATGTGCTGTTC-3'digested with the restriction enzyme BstN1 (MBI Fermentas, USA) at $37^{\circ} \mathrm{C}$ overnight, and then analyzed on 2.5\% agarose gel electrophoresis. A single band of 164 b. p. characterised mutant type $T$ allele, while the presence of three bands at 164, 136 and 28 b.p. or two bands at 136 and 28 b.p. only characterises heterozygous and homozygous wild variant respectively ( $\mathrm{C}$ allele is the wild allele). Positive and negative controls were used in the genotyping protocol and 5\% of randomly selected samples were re-genotyped by other lab member with 100\% concordance.

\section{STATISTICAL ANALYSIS}

All statistical analyses were performed by the standard methods using SPSS computer software (Version 13, SPSS Inc., Chicago, IL, USA). Results were expressed as means \pm standard deviations (SD). A two-tailed $p$ value $<$ 0.05 was considered statistically significant. Chi-square $\left(\chi^{2}\right)$ analysis was used to assess deviation from HardyWeinberg equilibrium (HWE) and to compare the genotype and allele frequency between patients and controls. Odds ratio (OR) were obtained by unconditional logistic regression analysis.

\section{RESULTS AND DISCUSSION}

\section{DEMOGRAPHIC DATA OF THE STUDY SUBJECTS}

A total of 179 HAV confirmed cases were included in the study. The male and female ratio was found out to be 17:9 for all the HAV cases together and so the male gender was predominant (65\%) (Table I). It was seen that the confirmed cases of HAV infection belonged mostly to the young adults in this region and so Hepatitis A frequently occurred in the young adults where mean age was calculated to be 25 years. Fulminant hepatic failure developed in 2.8\% of the Hepatitis A patients (Table II). Among the $179 \mathrm{HAV}$ patients, $11.2 \%$ patients had prolonged cholestasis during admission.

\begin{tabular}{|l|l|l|l|}
\hline \multicolumn{4}{|l|}{$\begin{array}{l}\text { Table 1: Clinical and laboratory characteristics of hepatitis A cases (n = 100) [ALT - } \\
\text { alanine transaminase; AST -amino serum transaminase] }\end{array}$} \\
\hline Parameter & $\begin{array}{l}\text { Acute Hepatitis } \\
\text { A }(\mathrm{n}=154)\end{array}$ & $\begin{array}{l}\text { HepatitisAwith } \\
\text { cholestasis }(\mathrm{n}=20)\end{array}$ & $\begin{array}{l}\text { Fulminant Hepatic } \\
\text { Failure (FHF) (n=5) }\end{array}$ \\
\hline Age & $25 \pm 7.12$ & $28 \pm 12.41$ & $34 \pm 10.44$ \\
\hline Sex ratio & $7: 4$ & $7: 3$ & $3: 2$ \\
\hline ALT(IU/L) $\leq 40$ & $468 \pm 171.24$ & $923 \pm 192.21$ & $4763.5 \pm 744.58$ \\
\hline AST(IU/L) $\leq 40$ & $252.33 \pm 220.94$ & $747.7 \pm 168.34$ & $4416 \pm 642.05$ \\
\hline $\begin{array}{l}\text { Prothrombin time(INR) } \\
(2.0-3.0)\end{array}$ & $1.20 \pm 0.60$ & $2.36 \pm 2.12$ & $8 \pm 0.56$ \\
\hline Total Bilirubin(mg/dl) $0.4-1.2$ & $5.37 \pm 0.84$ & $16.24 \pm 11.22$ & $18.40 \pm 11.30$ \\
\hline Total protein (gm/dl) 6.5-8 & $7 \pm 1.98$ & $7.95 \pm 1.16$ & $8.1 \pm 0.42$ \\
\hline
\end{tabular}


Table 2: Stratification of the Hepatitis A cases based on their clinical profile

\begin{tabular}{|l|l|}
\hline Cases & Frequency (case/total) \\
\hline Acute hepatitis A & $86(154 / 179)$ \\
\hline Hepatitis A with cholestasis & $11.2(20 / 179)$ \\
\hline Fulminant Hepatic Failure (FHF) & $2.8(5 / 179)$ \\
\hline
\end{tabular}

\section{ASSOCIATION OF TLR2 (RS5743708), TLR7 (RS179009) AND TLR9 (RS5743836) GENE VARIANTS WITH HAV INFECTION RISK}

The observed genotype frequencies in the study subjects were in agreement with Hardy Wienberg Equilibrium. To analyse the association between genetic variant with risk of HAV infection, the genotype frequency distribution of TLR2, 7 and 9 in HAV cases and control group was compared and shown in Table III.

The genotype and allele frequencies observed at this rs site 5743708 were in agreement with Hardy-Weinberg Equilibrium. There was no significant difference between the allelic and genotypic frequencies among the HAV cases and controls $(\mathrm{p}=0.4)[\mathrm{OR}=1.2(0.7063-2.276)$ at 95\% CI]. TLR2 rs5743708 wild variant GG was found more in controls compared to cases (37.6\% vs 33\%) but overall the heterozygous variant GA was most prevalent in both control and HAV cases (52.9\% and $34 \%$ respectively). The mutant variant AA was more prevalent in cases than controls (33\% vs 9.5\%). The variant allele A was found overall more in HAV cases compared to controls (67\% vs $62.4 \%$ ) (Table III).

The wild variant TT of TLR7 rs179009 frequency was higher in controls compared to HAV cases $(68.9 \%$ vs $67.6 \%$ ). The wild allele $\mathrm{T}$ was dominant in our study cohort $(78 \%$ and $74.6 \%$ in controls and HAV cases respectively). The mutant variant CC was comparatively less in both HAV cases and controls (18.4\% vs $12.9 \%)$. There was no significant difference between the allelic and genotypic frequencies among the HAV cases and controls $(p=0.9)$. The presence of mutant genotype CC did not significantly increased the risk of HAV infection compared to controls [OR=1.0(0.5619- 1.864) at 95\%CI] (Table III).

The wild variant CC frequency was higher in controls compared to HAV cases (69.4\% vs $17.3 \%)$. The mutant variant TT prevalence was very high in HAV cases compared to controls (76.6\% vs $2.4 \%)$. There was significant difference between the allelic and genotypic frequencies among the HAV cases and controls $(p<0.0001)$. The presence of mutant genotype TT significantly increased the

\begin{tabular}{|c|c|c|c|c|}
\hline & Controls $n=170$ & Patients $n=179$ & OR (95\%CI) & $\mathrm{p}$ value \\
\hline \multicolumn{5}{|c|}{ TLR2rs5743708 } \\
\hline GG & $64(37.6)$ & $59(33)$ & Ref & Ref \\
\hline GA & $90(52.9)$ & $61(34)$ & & \\
\hline $\mathrm{AA}$ & $16(9.5)$ & $59(33)$ & & \\
\hline $\mathrm{GA}+\mathrm{AA}$ & 62.4 & 67 & $1.2((0.7063-2.276)$ & 0.4 \\
\hline Allele G & $218(64.1)$ & $179(50)$ & Ref & \\
\hline Allele A & $122(35.9)$ & $179(50)$ & $1.78(1.011-\quad 3.156)$ & 0.04 \\
\hline \multicolumn{5}{|c|}{ TLR7rs179009 } \\
\hline TT & $117(68.9)$ & $121(67.6)$ & Ref & Ref \\
\hline CT & $31(18.2)$ & $25(14)$ & & \\
\hline $\mathrm{CC}$ & $22(12.9)$ & $33(18.4)$ & & \\
\hline $\mathrm{CT}+\mathrm{CC}$ & 31.1 & 32.4 & $1.0(0.5619-1.864)$ & 0.9 \\
\hline Allele T & $265(78)$ & $267(74.6)$ & Ref & Ref \\
\hline Allele C & $75(22)$ & $91(25.4)$ & $1.1(0.5981-2.234$ & 0.6 \\
\hline \multicolumn{5}{|c|}{ TLR9rs5743836 } \\
\hline $\mathrm{CC}$ & $118(69.4)$ & $34(17.3)$ & Ref & Ref \\
\hline $\mathrm{CT}$ & $48(28.2)$ & $93(6.1)$ & & \\
\hline TT & $4(2.4)$ & $52(76.6)$ & & \\
\hline $\mathrm{CT}+\mathrm{TT}$ & 30.6 & 82.7 & $10.2(5.30-20.29)$ & $<0.0001$ \\
\hline Allele C & $284(83.5)$ & $161(45)$ & Ref & Ref \\
\hline Allele T & $56(16.5)$ & $197(55)$ & $6.1(3.202-12.1)$ & $<0.0001$ \\
\hline
\end{tabular}




\begin{tabular}{|l|l|l|l|l|l|l|l|l|l|}
\hline \multicolumn{6}{|l}{$\begin{array}{l}\text { Table 4: Genotypic frequency of TLR2 gene variants and susceptibility to different HAV complications [Bold values } \\
\text { represent significant risk;0R Odds ratio;CI confidence interval]. }\end{array}$} \\
\hline \multirow{2}{*}{ Groups } & Genotype distribution (\%) & Allele frequencies (\%) & $\begin{array}{l}\text { Less common allele } \\
\text { frequency }\end{array}$ & $\begin{array}{l}\chi 2 \\
\text { (p value }\end{array}$ & Odds ratio (95\% CI) \\
\cline { 2 - 9 } & GG & GA & AA & G & A & ref & \\
\hline $\begin{array}{l}\text { Control } \\
(\mathrm{n}=170)\end{array}$ & $64(37.6)$ & $90(52.9)$ & $16(9.5)$ & $218(64.1)$ & $122(35.9)$ & $62.4 \%$ & 0.6 & $1.1(0.6296-2.005)$ \\
\hline $\begin{array}{l}\text { Acute } \\
\text { HAV(n=154) }\end{array}$ & $55(35.7)$ & $55(35.7)$ & $44(28.6)$ & $165(53.6)$ & $143(46.4)$ & $64.3 \%$ & 0.004 & $2.5(1.328-4.808)$ \\
\hline $\begin{array}{l}\text { HAVwith } \\
\text { cholestasis } \\
(\mathrm{n}=20)\end{array}$ & $4(20)$ & $4(20)$ & $12(60)$ & $12(30)$ & $28(70)$ & $80 \%$ & & \\
\hline $\begin{array}{l}\text { HAV caused } \\
\text { FHF (n=5) }\end{array}$ & $0(0)$ & $2(40)$ & $3(60)$ & $2(20)$ & $8(80)$ & $100 \%$ & $<0.0001$ & 0 \\
\hline
\end{tabular}

\begin{tabular}{|l} 
Table 5: Genotypic frequency of TLR7 gene variants and susceptibility to different HAV complications [Bold \\
values represent significant risk; OR Odds ratio;CI confidence interval]. \\
\hline Groups
\end{tabular}

risk of HAV infection compared to controls [OR $=10.2$ (5.30- 20.29) at 95\%CI] by several folds (Table III).

\section{ASSOCIATION OF TLR2(RS5743708), TLR7(RS179009) AND TLR9(RS5743836) GENE POLYMORPHISM WITH DIFFERENT HAV COMPLICATIONS}

The genotypic frequencies of the TLR2, TLR7 and TLR9 SNP's were correlated with the two HAV case groups ie HAV with cholestasis and HAV caused FHF to investigate whether any possible association is implicated between the polymorphisms and the HAV complications.

In case of different HAV case groups, the presence of variant allele A of TLR2 rs5743708 significantly increased the risk of cholestasis compared to controls $(\mathrm{p}=0.004)$ $[\mathrm{OR}=2.5(1.328-4.808)$ at $95 \% \mathrm{CI}]$ and non significantly compared to Acute HAV ( $\mathrm{p}=0.6)[\mathrm{OR}=1.1(0.6296-2.005)$ at $95 \% \mathrm{CI})$ and HAV caused FHF $(\mathrm{p}<0.0001)$ [OR $=0$ at $95 \% \mathrm{CI}$ ) . The variant allele was most prevalent in FHF cases $(100 \%)$ compared to controls and other HAV case groups (Table IV).

When the distribution of TLR7 rs 179009 was studied in the different HAV case groups, the data showed that presence of the wild variant TT was higher in acute HAV cases (70.1\%) compared to the controls (68.9\%) and HAV with cholestasis (65\%), but was not found in the FHF cases $(0 \%)$. The mutant variant allele $C$ was most prevalent in FHF cases (90\% vs 22\%) compared to controls. The mutant variant CC was associated significantly with HAV caused FHF $(p<0.0001)$ and was not found to be a risk factor $(\mathrm{OR}=0)$. This polymorphism is also not significantly associated with acute HAV $(\mathrm{p}=0.8)$ and HAV with cholestasis ( $p=0.5)$, and did not significantly increase the risk of acute HAV $[\mathrm{OR}=0.9(0.52-1.749)$ at $95 \% \mathrm{CI}]$ and HAV with cholestasis $[\mathrm{OR}=1.1(0.6589-2.162)$ at $95 \%$ CI] (Table V).

The distribution of TLR9 rs5743836 in the different HAV case groups showed that presence of the wild variant CC was higher in controls (69.4\%) compared to the acute HAV (17.5\%) and HAV with cholestasis (30\%), and FHF cases (20\%) . The heterozygous mutant variant CT was most prevalent in FHF cases (80\% vs $28.2 \%$ ) compared to controls and other case groups. The overall mutant variant $(\mathrm{CT}+\mathrm{TT})$ was more prevalent in the HAV case groups rather than the controls. The presence of the mutant allele $\mathrm{T}$ significantly increased the risk of acute HAV $[\mathrm{p}<0.0001 ; 0 \mathrm{R}=10.07(5.242-19.97)$ at $95 \% \mathrm{CI}]$, 
HAV with cholestasis $[p<0.0001 ; 0 R=5.05$ (2.784- 9.324) at $95 \% \mathrm{CI}]$ and $\mathrm{FHF}(\mathrm{P}<0.0001 ; \mathrm{OR}=8.5(4.542-16.64)$ at 95\% CI) (Table VI).

There is ever increasing evidence suggesting the role of host genetic factors on the different outcomes of hepatitis infection (Thurz., 2001; Lin et al., 1989). The TLR pathways have been implicated to play important roles in innate immunity against different types of pathogens in humans (Isogawa et al., 2005; Hoebe et al., 2003; Kurt-Jones et al., 2004).

Understanding the host immune factors and its interaction with the virus may improve the Hepatitis A disease management. Genetic studies on the TLR2 gene have identified a number of polymorphisms which have been shown to affect host defense and disease progression (Chen et al., 2010; Takeda et al., 2003).

Studies have shown the possible involvement of TLR9 in the pathogenesis of human hepatitis (Jiang et al., 2009). The TLR7 gene is located on the X-chromosome, covering a region of three exons (Du et al., 2000).TLR7 have been thought to play a pivotal role in the immune response against HAV infection as it can bind ssRNAs leading to the production of large amounts of the antiviral cytokine interferon- $\alpha$ via dendritic cells (Colonna et al., 2002).

This is the first study of its kind in this region which shows that TLR2 rs5743708 mutant allele A was significantly associated with Hepatitis A infection and the mutant variant 'A' was prevalent in our study cohort ie in the polpulation of this region (both control and patient groups).The genotypic variants $\mathrm{AA}$ and $\mathrm{GA}+\mathrm{AA}$ was also found to be risk factor for HAV caused cholestasis. The mutant variants $(\mathrm{TT}+\mathrm{CT})$ was most prevalent for TLR9 rs5743836 in our study cohort and the mutant variant $\mathrm{T}$ was found to be a significant risk factor for HAV infection and was significantly associated with acute HAV, Cholestasis and FHF. TLR7 rs179009 mutant variant CC was highly prevalent in the study and patient groups and the mutant genotypes CC and TC was not significantly associated with HAV infection and was not a risk factor for the same.

There was certain limitation in our study that needs to be addressed. The sample number in this study was moderate and so other large population-based studies are needed to validate the findings.In summary, our results provide first evidence for the TLR2 rs5743708 polymorphism as a host factor affecting HAV infection and thus the disease severity. Ultimately, such studies may also offer an opportunity to find out how TLR-mediated signals might be used as future therapeutic targets.

\section{ACKNOWLEDGEMENTS}

This first author thanks the Dept of Science and Technology (DST) for INSPIRE Fellowship.
The authors declare that they have no conflict of interest.

\section{CONFLICT OF INTEREST}

All authors declare that they have no conflict of interest and also no financial interests relevant to the subject of the manuscript.

\section{REFERENCES}

Aderem A., and Ulevitch R.J. (2000) Toll-like receptors in the induction of the innate immune response. Nature Vol 406:782787.

Buggs AM ( 2016).E Medicine Med Scape .com Updated Dec 2016 International Conference on Viral Hepatitis (ICVH) 2016

Chen Y.C., Hsiao C.C., Chen C.J., Chin C.H., Liu S.F., Wu C.C., (2010) Toll-like receptor 2 gene polymorphisms, pulmonary tuberculosis, and natural killer cell counts. BMC Med Genet 11: 17.

Colonna M., Krug A., and Cella M. (2002) Interferon-producing cells: on the front line in immune responses against pathogens. Curr Opin Immunol Vol 14:373-379.

Du X., Poltorak A., Wei Y., and Beutler B. (2000) Three novel mammalian toll-like receptors: gene structure, expression, and evolution. Eur Cytokine Netw Vol 11:362-371.

Eid A.J., Brown R.A., Paya C.V., and Razonable R.R. (2007) Association between toll-like receptor polymorphisms and the outcome of liver transplantation for chronic hepatitis $C$ virus. Transplantation Vol 84:511-516.

Glikson M., Galun E., Oren R., (1992) Relapsing hepatitis A. Review of 14 cases and literature survey. Medicine Vol 71: 14-23.

Hill A.V. (2001) The genomics and genetics of human infectious disease susceptibility. Annu Rev Genomics Hum Genet Vol 2:373-400.

Hoebe K., Du X., Georgel P., (2003) Identification of Lps2 as a key transducer of MyD88-indepandent TIR signaling. Nature Vol 424:743-8.

Hong J., Leung E., Fraser A.G., Merriman T.R., Vishnu P., and Krissansen G.W. (2007) TLR2, TLR4 and TLR9 polymorphisms and Crohn's disease in a New Zealand Caucasian cohort. J Gastroenterol Hepatol Vol 22:1760-1766.

Isogawa M., Robek M.D., Furuichi Y., and Chisari F.V. (2005) Toll-like receptor signaling inhibits hepatitis B virus replication in vivo. J Virol Vol 79:7269-72.

Jiang W., Sun R., Zhou R., Wei H., and Tian Z. (2009) TLR-9 Activation Aggravates Concanavalin A-Induced Hepatitis via Promoting Accumulation and Activation of Liver CD4+ NKT Cells. The Journal of Immunology Vol 182 No 6 : 37683774.

Jung Y.M., Park S.J., Kim. J.S., (2010) Atypical manifestations of hepatitis A infection: a prospective, multicenter study in Korea. J Med Virol Vol 82:1318-1326. 
Kijpittayarit S., Eid A.J., Brown R.A., Paya C.V., and Razonable R.R . (2007)Relationship between Toll-like Receptor 2 polymorphism and cytomegalovirus disease after liver transplantation. Clin Infect Dis Vol 44:1315-1320.

Kurt-Jones E.A., Popova L., Kwinn L., (2004) Pattern recognition receptors TLR4 and CD14 mediate response to respiratory syncytial virus. Nat Immunol Vol 101:5598-603.

Lachheb J., Dhifallah I.B., Chelbi H., Hamzaoui K., and Hamzaoui A. (2008) Toll-like receptors and CD14 genes polymorphisms and susceptibility to asthma in Tunisian children. Tissue Antigens Vol 71:417-425.

Lazarus R., Klimecki W.T., Raby B.A., Vercelli D., Palmer L.J., Kwiatkowski D.J., et al. (2003) Single-nucleotide polymorphisms in the Toll-like receptor 9 gene (TLR9): frequencies, pairwise linkage disequilibrium, and haplotypes in three U.S. ethnic groups and exploratory case-control disease association studies. Genomics Vol 81:85-91.

Lin T.M., Chen C.J., Wu M.M., (1989) Hepatitis B virus markers in Chinese twins. Anticancer Res Vol 9:737-42.

Lorenz E., Mira J.P., Cornish K.L., Arbour N.C., and Schwartz D.A . (2000) A Novel Polymorphism in the Toll-Like Receptor 2 Gene and Its Potential Association with Staphylococcal Infection. Infect Immunol Vol 11:6398-6401.

Medzhitov R . (2001) Toll-like receptors and innate immunity. Nat Rev Immunol Vol 1:135-145.

MMWR Morb Mortal Wkly Rep. (1996) Prevention of hepatitis A through active or passive immunization: Recommendations of the Advisory Committee on Immunization Practices (ACIP). Vol 45 No 15:1-30.

Mollaki V., Georgiadis T., Tassidou A., Ioannou M., Daniil Z., Koutsokera A., (2009) Polymorphisms and haplotypes in TLR9 and MYD88 are associated with the development of Hodgkin's lymphoma: a candidate-gene association study. J Hum Genet Vol 54:655-659.

Ogus A.C., Yoldas B., Ozdemir T., Uguz A., Olcen S., Keser I., Coskun M., (2004) The Arg753Gln polymorphism of the human toll-like receptor 2 gene in tuberculosis disease. Eur Respir J Vol 23: 219-223.

Pandey S., and Agrawal D.K . (2006) Immunobiology of tolllike receptors: emerging trends. Immunol Cell Biol Vol 84:333341.

Polso J., Lee W.M. (2005) American Association for the Study of Liver Disease. AASLD position paper: the management of acute liver failure. Hepatology Vol 41:1179-1197.

Schro"der N.W., and Schumann R.R . (2005) Single nucleotide polymorphisms of Toll-like receptors and susceptibility to infectious disease. Lancet Infect Dis Vol 5:156164.

Takeda K., Kaisho T., and Akira S. (2003) Toll-like receptors. Annu Rev Immunol Vol 21: 335-76.

Thursz M .(2001) Genetic susceptibility in chronic viral hepatitis. Antiviral Res Vol 52:113-6.

Torok H.P., Glas J., Tonenchi L., Bruennler G., Folwaczny M., and Folwaczny C. (2004) Crohn's disease is associated with a toll-like receptor-9 polymorphism. Gastroenterology Vol 127:365-366.

Weltzler L.M . (2003) The role of Toll-like receptor 2 in microbial disease and immunity. Vaccine Vol 21:S55-S60.

Yokosuka 0. (2000) Molecular biology of hepatitis a virus: significance of various substitutions in the hepatitis A virus genome. J Gastroenterol Hepatol Vol 15 :D91-D97. 